\title{
Efficacy and safety of anti-vascular endothelial growth factor therapies in older patients for first line treatment of metastatic renal cell carcinoma
}

\author{
Hugo Georges Arthur Dupuis ${ }^{1 \wedge}$, Ala Chebbi ${ }^{1}$, Louis Surlemont ${ }^{1}$, Olivier Rigal ${ }^{2}$, Frédéric Di Fiore ${ }^{2}$, \\ Christian Pfister ${ }^{1,3}$, François-Xavier Nouhaud ${ }^{1,3}$ \\ ${ }^{1}$ Urology Department, Rouen University Hospital, Rouen, France; ${ }^{2}$ Medical Oncology Unit, Henri Becquerel Center, Rouen, France; ${ }^{3}$ Clinical \\ Investigation Center, Inserm 1404, Onco Urology, Rouen, France \\ Contributions: (I) Conception and design: HGA Dupuis, FX Nouhaud; (II) Administration support: FX Nouhaud; (III) Provision of study materials or \\ patients: O Rigal, F Di Fiore, C Pfister, FX Nouhaud; (IV) Collection and assembly of data: HGA Dupuis, A Chebbi, L Surlemont; (V) Data analysis \\ and interpretation: HGA Dupuis; (VI) Manuscript writing: All authors; (VII) Final approval of manuscript: All authors. \\ Correspondence to: Hugo Georges Arthur Dupuis. Urology Department, Rouen University Hospital, 1 rue de Germont, 76031 Rouen, France. \\ Email: hugo.dupuis@chu-rouen.fr.
}

Background: immunotherapy became the first line treatment of metastatic renal cell carcinoma (mRCC). Nevertheless, a better understanding of the specificities of targeted therapies (TT) in the elderly population could be helpful in order to improve the management of mRCC in this population. The aim of this retrospective study was to assess efficacy and safety of sunitinib and sorafenib used as first-line TT in 70 years older patients compared to younger patients.

Methods: Data were retrospectively collected for all consecutive mRCC patients receiving first line TT treatment by sunitinib or sorafenib for mRCC from January 2006 to November 2017. Patients were divided into two groups according to the age using a cut-off at 70 years old. Median progression-free survival (PFS) and overall survival (OS) were estimated by Kaplan-Meier method and compared using log-rank test.

Results: In total, 147 patients were included; 94 (63.9\%) were $<70$ and 53 (36.1\%) were 70 years old or more. First line TT used was sunitinib in 123 (83.7\%) patients or sorafenib in $24(16.3 \%)$ patients. Median PFS was 8 months for elderly patients vs. 6 in younger group $(\mathrm{P}=0.68)$. Median OS were 26 vs. 36 months $(\mathrm{P}=0.08)$. Severe induced toxicity was more frequent among elderly patients: $34(64.2 \%)$ vs. 46 patients (48.9\%) ( $\mathrm{P}=0.07)$. Rate of treatment discontinuation due to toxicity was 22 patients $(23.4 \%)$ in younger group vs. 28 patients $(52.8 \%)$ in the elderly group $(\mathrm{P}=0.0005)$. Results were similar in the 2 groups regarding the type of toxicities.

Conclusions: Our results suggest similar efficacy of anti-vascular endothelial growth factor (VEGF) agents as first-line treatment for mRCC among younger and older patients with an age cut-off of 70 years. Safety results suggest that these drugs can be safely used for older patients with a need of caution regarding toxicity prevention.

Keywords: Renal cell carcinoma (RCC); older patient; targeted therapy (TT); metastatic; efficacy

Submitted Dec 06, 2020. Accepted for publication Mar 17, 2021.

doi: $10.21037 /$ tau-20-1481

View this article at: http://dx.doi.org/10.21037/tau-20-1481

^ ORCID: 0000-0001-6056-4906. 


\section{Introduction}

Renal cell carcinoma (RCC) represents $2-3 \%$ of malignant cancers with an increasing incidence worldwide, especially in western countries (1). Today immunotherapies represents the main option for first line treatment (2). However, targeted therapies (TT) [anti-vascular endothelial growth factor (VEGF) therapies] remain essential for the subsequent lines in the treatment sequence of mRCC patients. The efficacy and safety of these drugs were largely documented in pivotal trials. Different studies have suggested that age remains a risk factor and most of diagnoses are made between 60 and 70 years old (3).

Elderly patients represent a significant proportion of the RCC population as 331,582 prevalent cases older than 70 in 2018 (4). Regarding metastatic disease, $20-30 \%$ of all RCC are metastatic (mRCC) at diagnosis while $20 \%$ of patients with initially localized RCC will encounter metastatic recurrence during follow-up. Specific data regarding the management of TT in elderly patients are scarce (5). Whereas they represent a particular population with an increased incidence of comorbidities as chronic kidney disease (CKD) or liver dysfunction, as well as polymedication. These parameters may impact the efficacy and safety of TT in this population as well as limit the use of immunotherapies (6). A better understanding of the specificities regarding the efficacy and toxicity of TT in the elderly population could be helpful in order to improve the management of mRCC in this population. The aim of this retrospective study was to assess efficacy and safety of sunitinib and sorafenib used as first-line TT in patients $>70$ years old compared to younger patients.

We present the following article in accordance with the STROBE reporting checklist (available at http://dx.doi. org/10.21037/tau-20-1481) (7).

\section{Methods}

\section{Study population}

All consecutive mRCC patients $>18$ years receiving first line TT treatment by sunitinib or sorafenib for mRCC from January 2006 to November 2017 were included in a unique center. All clinical and tumor baseline characteristics were retrospectively collected for each patient, including toxicity related to treatment. Sunitinib was orally administered for 4 consecutive weeks, followed by a 2 -week break (dose of $50 \mathrm{mg} /$ day), whereas sorafenib was orally administered continuously at $400 \mathrm{mg}$ twice daily. Patients underwent physical examination associated with blood cell count and serum chemistry tests at baseline and on days 14 and 28 of the first treatment cycle and at least monthly during TT exposure. Results were analyzed according to normal institutional values. For patients treated by sunitinib, an electrocardiogram (ECG) was performed at baseline. All the toxicities were graded according to NCI-CTCAE, version 3.0. When grade 3 non-hematological toxicity occurred, treatment was interrupted until toxicity was resolved and the dose was reduced thereafter by one level at the physician's discretion. Treatment was definitively stopped in case of grade 4 non-hematological toxicity. Toxicity was classified as 'mild to moderate' corresponding to grade 0 to 2 toxicity or 'severe' corresponding to grade 3 to 4 toxicity. Baseline comorbidities were collected and analyzed according to the Charlson score (8). The prognostic score of each patient was calculated from the 6 clinical and biological data composing the International Metastatic Renal Cell Carcinoma Database Consortium model (IMDC) (9). These data were Karnofsky performance status (KPS), time from diagnosis to first-line TT, haemoglobin concentration, neutrophil count, platelet count, and serum calcium concentration. Follow-up was based on a physical examination and CTscan performed every 3 months. Response was evaluated using Response Evaluation Criteria in Solid Tumors (10). There were no missing data for any of the patients included in the study. The study was conducted in accordance with the Declaration of Helsinki (as revised in 2013). The study was approved by institutional ethics committee of CHU de Rouen (No.: E2021-22) and individual consent for this retrospective analysis was waived.

\section{Statistical analysis}

Patients were divided into two groups according to the age with a cut-off at 70 years old. This cut-off was previously used in analysis of elderly sunitinib-treated patients or sorafenib-treated patient with mRCC (11-13). Patients characteristics were compared between the age groups using Chi-2 test as appropriate. Overall survival (OS) was defined as time from treatment initiation to date of death because of any cause or censored at the last follow-up. Progressionfree survival (PFS) was defined as time from treatment initiation to date of disease progression according to the RECIST criteria or clinically. Median PFS and OS for comparison of sunitinib or sorafenib-treated patients aged 70 or $>70$ years were estimated by Kaplan-Meier method and compared using log-rank test. The limit of significance 


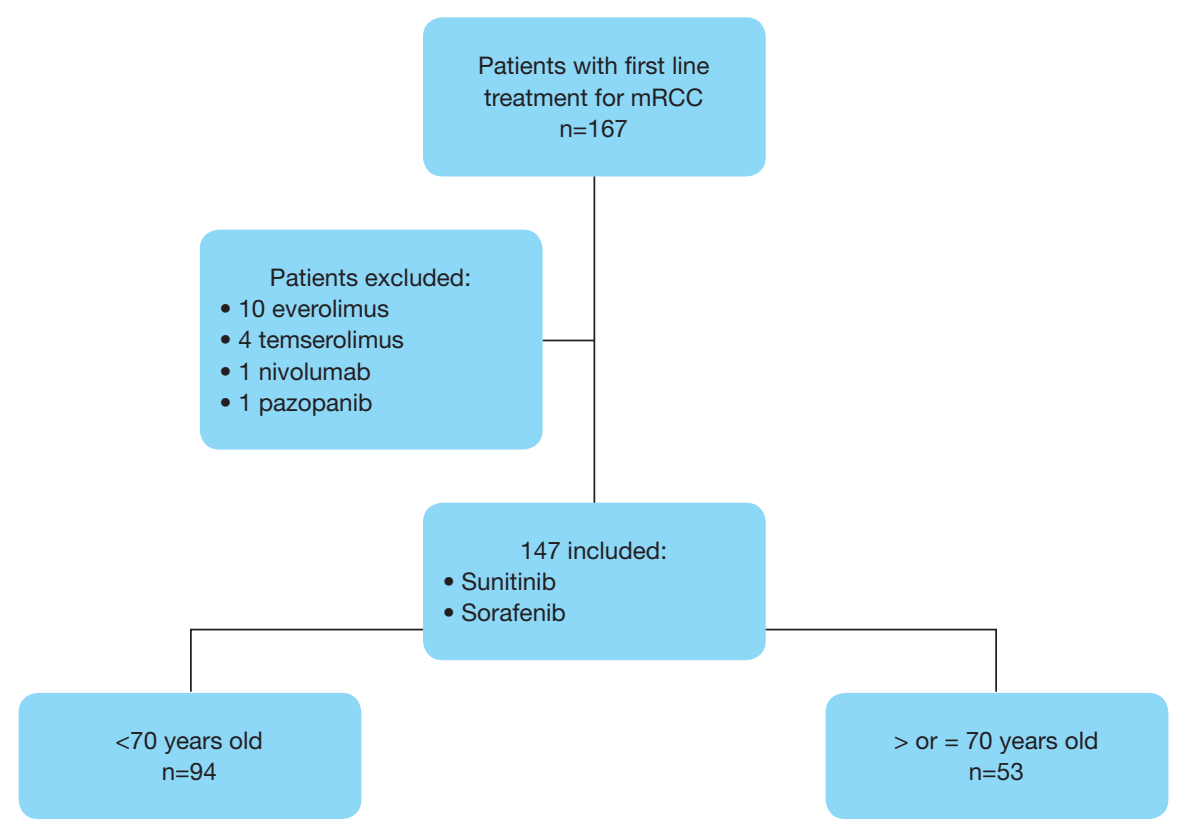

Figure 1 Flow chart. mRCC, metastatic renal cell carcinoma.

was fixed at $\mathrm{P}$ value less than 0.05 . Statistical analyses were carried out using Medcalc version 12.0 (Medcalc software bvba, Ostend, Belgium).

\section{Results}

\section{Baseline characteristics}

A total of 167 patients with a first line treatment for mRCC were reviewed. Only those treated with sunitinib or sorafenib were included, representing 147 patients (Figure 1). 94 (63.9\%) were men; 94 (63.9\%) were <70 and $53(36.1 \%)$ were $>70$ years (Table 1$)$. The median age in the $<70$ and the $>70$ age group was 58.5 years (range, $38-69$ years) and 74 years (range, 70-87 years) respectively. First line TT used was sunitinib in 123 (83.7\%) patients or sorafenib in $24(16.3 \%)$ patients. The predominant histology was clear cell renal carcinoma (131 patients, $89 \%$ ). As reported in Table 1, baseline characteristics were mainly similar. However, significant differences between the two groups were found. Patients $>70$ years had a higher incidence of CKD (defined by GFR $<60 \mathrm{~mL} / \mathrm{min}$ ). More patients $<70$ years presented thrombocytosis and/or high neutrophil count than in the $>70$ years old age group (respectively $14.8 \%$ vs. $3.77 \%, \mathrm{P}=0.0431$ ). Intermediate IMDC score were significantly higher in the $>70$ years old group. Treatment related toxicity was more frequently the reason for treatment discontinuation in the elderly group: $28(52.8 \%)$ patients $v s .22(24.4 \%)$ in the younger patients group $(\mathrm{P}=0.002)$. The median follow-up was 21 months for the both groups.

\section{Survival analysis}

The survival was similar between the two groups. The median PFS was 8 months in the $>70$ years old groups $v s .6$ in the younger patients group $(\mathrm{P}=0.68)$ (Figure 2). Similarly, median OS were not significantly different between the two groups (respectively 26 vs. 36 months, $\mathrm{P}=0.08$ ) (Figure 3).

\section{Toxicity}

A total of 80 patients $(54.4 \%)$ encountered one or more severe treatment-induced toxicity event; $79.5 \%$ of the major toxicity events occurred during the first five months following treatment-initiation (Figure 4). The incidence of severe induced toxicity was found with a trend to be more frequent among elderly patients: 34 patients $(64.2 \%) v s .46$ patients (48.9\%) $\mathrm{P}=0.07$. For 50 patients (34\%) the first line TT was definitely stopped due to treatment-induced toxicity. A significant difference between the two groups was found for the rate of treatment discontinuation due to toxicity with respectively 22 patients (23.4\%) in the younger group $v s .28$ 
Table 1 Clinical and tumor baseline characteristics

\begin{tabular}{|c|c|c|c|}
\hline Characteristics & $<70$ years old $(\mathrm{n}=94), \mathrm{n}(\%)$ & $>70$ years old $(n=53), n(\%)$ & $\mathrm{P}$ \\
\hline Karnofsky index <80\% & $34(36.2)$ & $24(45.3)$ & 0.27 \\
\hline \multicolumn{4}{|l|}{ Comorbidity } \\
\hline Charlson score $>2$ & $38(40.4)$ & $30(56.6)$ & 0.06 \\
\hline Diabetes & $14(14.9)$ & $9(17.0)$ & 0.92 \\
\hline Obesity & $22(23.4)$ & $8(15.1)$ & 0.32 \\
\hline Clear cell carcinoma & $85(90.4)$ & $46(86.8)$ & 0.81 \\
\hline Metastatic at diagnosis & $46(48.9)$ & $20(37.7)$ & 0.2 \\
\hline \multicolumn{4}{|l|}{ Type of targeted therapy } \\
\hline Sunitinib & $75(79.8)$ & $48(90.6)$ & 0.14 \\
\hline Sorafenib & $19(20.2)$ & $5(9.4)$ & 0.14 \\
\hline Anemia & $29(30.9)$ & $16(30.2)$ & 0.93 \\
\hline Thrombocytosis & $14(14.9)$ & $2(3.8)$ & $0.038^{*}$ \\
\hline High neutrophil count & $19(20.2)$ & $5(9.4)$ & $0.043^{*}$ \\
\hline Hypercalcemia & $8(8.5)$ & $1(1.9)$ & 0.1 \\
\hline LDH >1.5 ULN & $14(14.9)$ & $5(9.4)$ & 0.34 \\
\hline Poor & $28(29.8)$ & $8(15.1)$ & \\
\hline
\end{tabular}

*, $\mathrm{P}<0.05$. TT, targeted therapy; LDH, lactates dehydrogenase; ULN, upper limit of normal.

patients $(52.8 \%)$ in the elderly group $(\mathrm{P}=0.0005)$. Finally, results were similar in the 2 groups regarding to the type of induced toxicities. Especially, no significant difference was found for dermatologic and digestive toxicity as well as fatigue and hypertension (Table 2).

\section{Discussion}

As mentioned, literature data about the use of tyrosine kinase inhibitor (TKI) for the treatment of mRCC in elderly patients is scarce. study emphasized the fact that despite high cancer frequency in this population there is a lack of data as well as a fear of side effect and a minimization of potential benefit (5). Data come from clinical trials involving a selected population not representative of elderly population. In this study we report further informations about this topic. Especially we showed that the efficacy and the safety of sunitinib and sorafenib for patients older than 70 could be comparable to younger patients as we found no difference in terms of OS and PFS as well as toxicity.

Regarding the survival outcomes, no significant difference was found for PFS with median at 8 vs. 6 months $(\mathrm{P}=0.68)$ or 


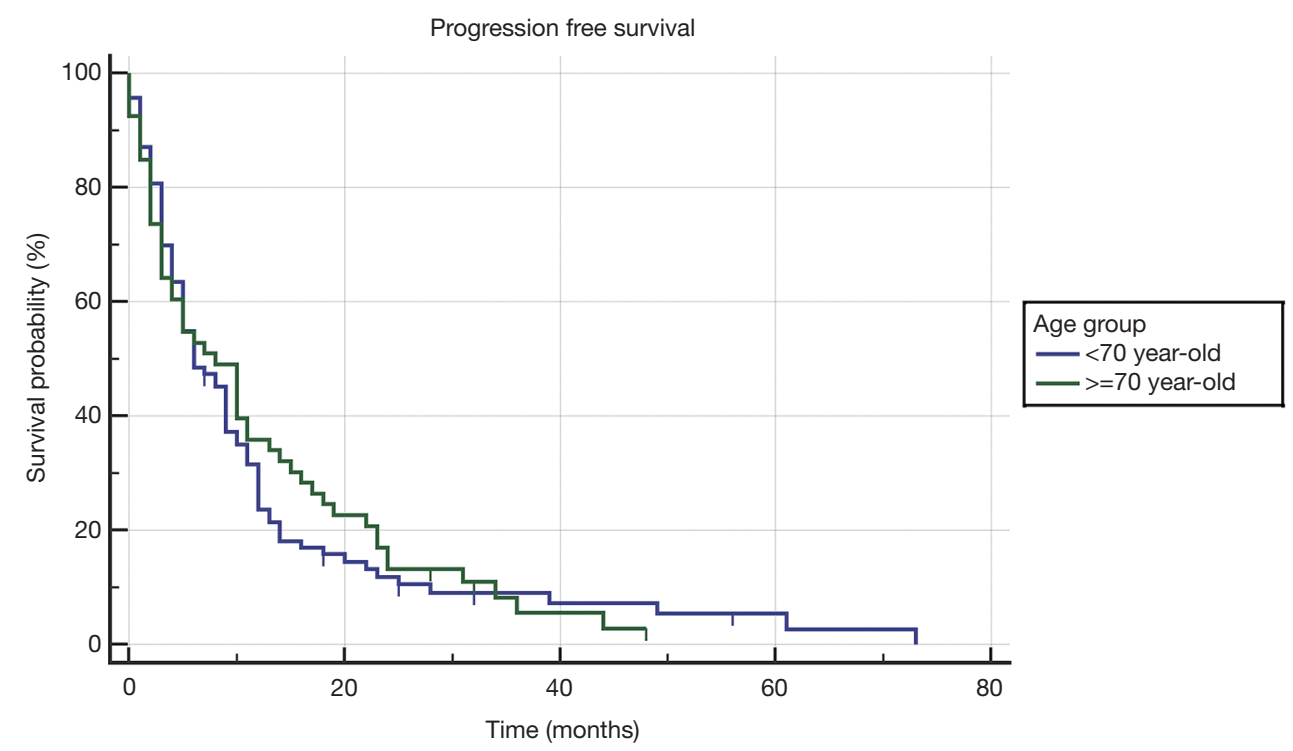

Figure 2 Relationship between progression probability and time according to the age.

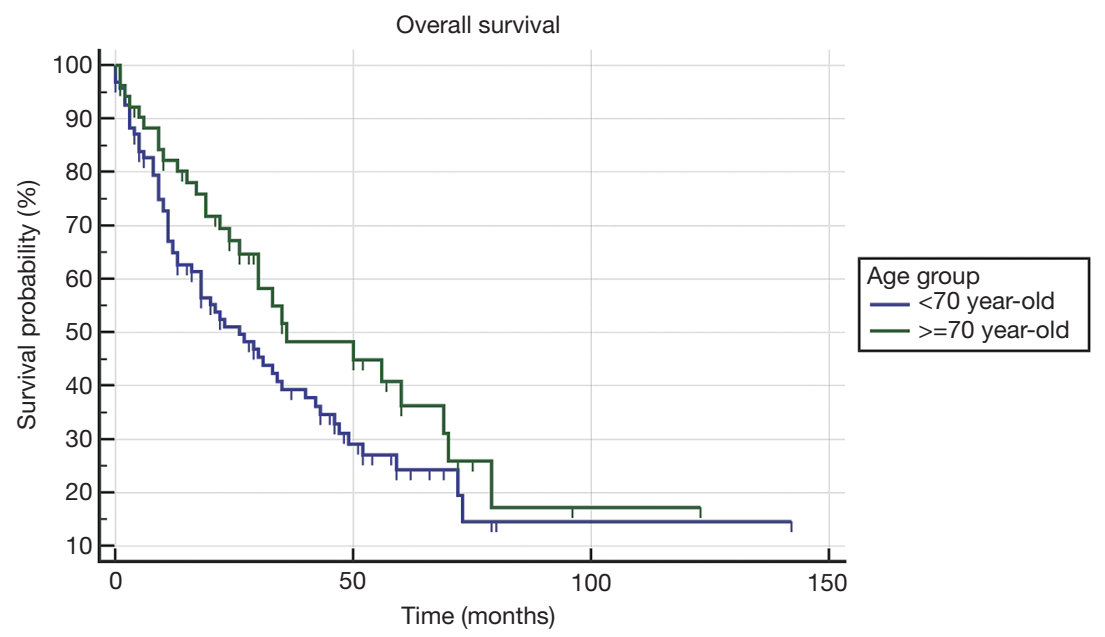

Figure 3 Relationship between survival probability and time according to the age.

median OS, respectively 26 vs. 36 months, $(\mathrm{P}=0.08)$.

An evolution in the management of toxicities could be underline, with better results especially in elderly population. These results were close to those previously reported on sunitinib or sorafenib treatment in this elderly population. In this context, Hutson et al. found no difference regarding the efficacy of sunitinib in terms of survival between age groups similar to ours (11) (Table 3). Similarly, Poprach et al. reported more recently comparable results in a retrospective cohort of 1,315 patients treated with sunitinib (14). In addition, using a different age cut-off did not suggested different results: using a cut off age at 65 years old, Gore et al. also described similar survival between the 2 groups with sunitinib (15). Regarding the molecule used, our cohort was mainly based on sunitinib $83.7 \%$. Only $16.3 \%$ of the patients received sorafenib as first line treatment, this was due to a temporary authorization to use sorafenib in 2006 in this indication at our institution while waiting for sunitinib to be available from mid-2007. Sunitinib was then used as the standard treatment for first line mRCC. Literature data regarding the use of Sorafenib in elderly patients are even rarer and mainly issued from 


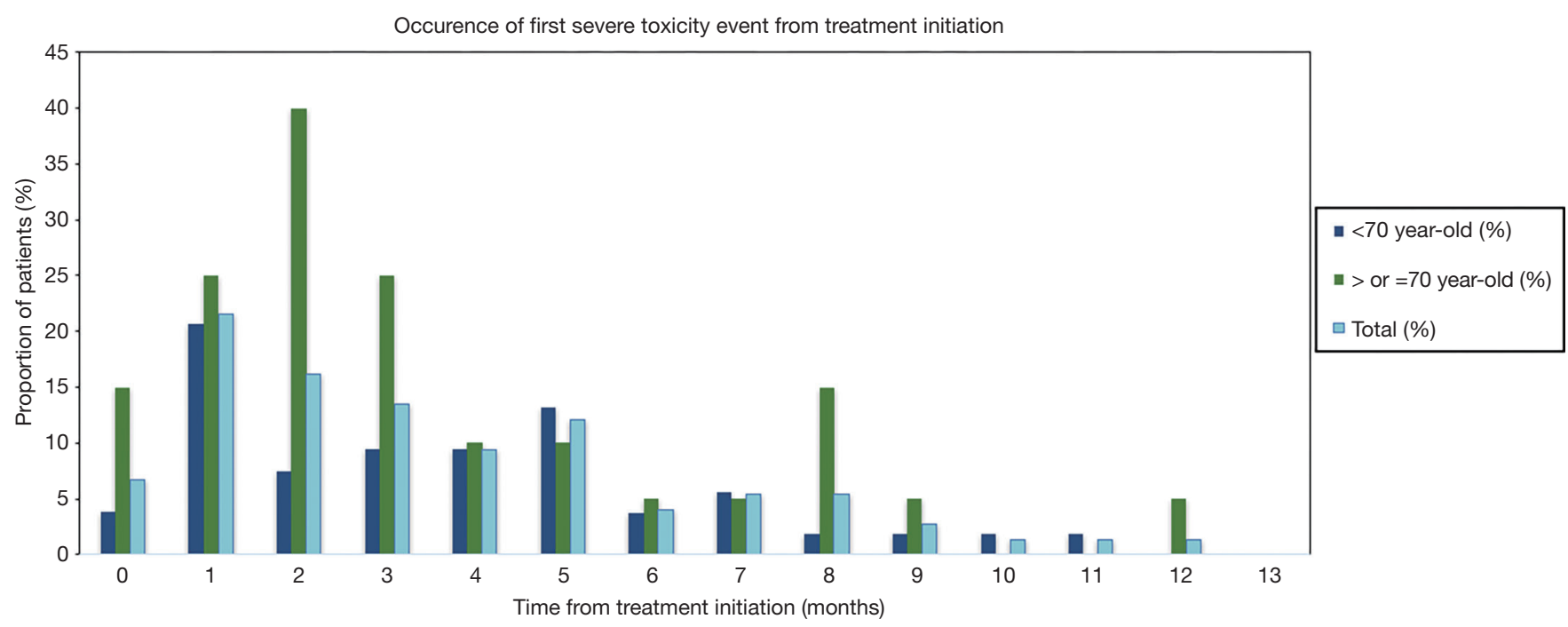

Figure 4 Occurrence of first severe toxicity event from treatment initiation.

Table 2 Detailed toxicities according to the age

\begin{tabular}{lccc}
\hline Variables & $<70$ years old $(\mathrm{n}=94), \mathrm{n}(\%)$ & $>70$ years old $(\mathrm{n}=53), \mathrm{n}(\%)$ & $\mathrm{P}$ \\
\hline Grade 3/4 toxicity events & $46(48.9)$ & $34(64.2)$ & $29(54.7)$ \\
Dermatologic (all) & $60(63.8)$ & $31(58.5)$ & 0.07 \\
Digestive (all) & $53(56.4)$ & $27(50.9)$ & 0.94 \\
Fatigue & $35(37.2)$ & $12(22.6)$ & 0.14 \\
Cardiovascular (all) & $20(21.3)$ & $9(17.0)$ & $5(9.4)$ \\
hematological & $10(10.6)$ & $3(5.7)$ & 0.39 \\
Renal (all) & $13(13.8)$ & $4(7.5)$ \\
Hypothyroidism & $8(8.5)$ & $0(0)$ \\
Neurologic (all) & $1(1.1)$ & 0.6 \\
Respiratory (all) & $2(2.1)$ & 0.76 \\
\hline
\end{tabular}

second line treatment studies. Eisen et al. reported similar outcomes for sorafenib as a second-line treatment between younger and older patients (>70 years) (12). Similar results were also found by Bukowski et al. and Procopio et al. $(13,16)$ (Table 3).

Our results showed no significant difference in terms of incidence of treatment-induced toxicity; $54.4 \%$ of our population encountered severe toxicity events with a majority of them occurring during the first five months following treatment initiation (Figure 3). A trend was noticed with a higher incidence of these events among elderly patient than younger patients, respectively $64.2 \%$ vs. $48.9 \%$
$(\mathrm{P}=0.07)$. This trend could be related to the higher rate of $\mathrm{CKD}$ in the older group. We previously reported the role of GFR less than 60 in mRCC as risk factor of TT-induced toxicities (17). Moreover, severe TT-induced toxicities were identified as an independent prognostic factor of TTF and OS. In addition, it is interesting to note that severe toxicity was significantly more likely to cause treatment discontinuation in the elderly group $(52.8 \%$ vs. $24.4 \%$, $\mathrm{P}=0.002)$. This suggest that even if the severe toxicity is not significantly more frequent in the elderly group, its occurrence significantly impacts more this population. This fact highlights the potential need to be cautious in 





the management of these drugs for this fragile population. The improvement made during the last years regarding the management of tolerability of anti-VEGF agents, inherited from the more than a decade experience of the use of these drugs are of real interest to optimize the tolerability of the treatment for the elderly patients. Hutson et al. reported comparable safety results between $<70$ and $>70$ years old groups (11). Nevertheless, they noticed some exceptions as a higher incidence of fatigue, cough, peripheral edema, anemia, decreased appetite, and thrombocytopenia in older patients (Table 3). Similarly, safety results of Poprach et al. and Gore et al. were not different between the age groups $(14,15)$. This last one observed a higher incidence for nonhematological grade 3-4 adverse events (AEs) in >70 years old group (Table 3). Regarding sorafenib-related toxicity the results reported in the literature were rare but consistent. Although Eisen et al. observed higher grade 3 toxicity and treatment-discontinuation rates, no significant difference was described between younger and older patients (12). These results were in agreement with two retrospective studies of Procopio et al. and Bukowski et al. finding no difference regarding treatment-induced toxicity $(13,16)$ (Table 3). In Table 3 we reported literature data obtained from studies assessing the outcomes of anti-VEGF agent in elderly patients $(18,19)$.

Our results confirmed the recent review from Neuzillet et al. regarding the specificities of cancer management in elderly patients. This review was also highlighting the possibility to safely use anti-VEGF in the elderly subject at the same doses as in the young subject with increased vigilance for side effects (20).

The main limitation of our study was of course its retrospective design with a small population because of unicentric characteristic. It was a trend regarding the overall survival, however, the comparison of the OS between two groups with different ages is difficult since the baseline life expectancy is not comparable between the groups. Cancer specific survival would have been more relevant, however, due to the retrospective nature of the study, this information was not available to allow us to assess it.

\section{Conclusions}

Our results suggest similar efficacy of anti-VEGF agents as first-line treatment for mRCC among younger and older patients with an age cut-off of 70 years. In addition, results about safety were close between the groups in term of incidence of severe toxicity events. However, the occurrence of such severe toxicity was significantly more impacting the treatment scheme for the older patients with higher rate of treatment discontinuation. This suggest that these drugs can be safely used for the older patients with a need of caution regarding toxicity prevention.

\section{Acknowledgments}

Funding: None.

\section{Footnote}

Reporting Checklist: The authors have completed the STROBE reporting checklist. Available at http://dx.doi. org/10.21037/tau-20-1481

Data Sharing Statement: Available at http://dx.doi. org/10.21037/tau-20-1481

Peer Review File: Available at http://dx.doi.org/10.21037/ tau-20-1481

Conflicts of Interest: All authors have completed the ICMJE uniform disclosure form (available at http://dx.doi. org/10.21037/tau-20-1481). The authors have no conflicts of interest to declare.

Ethical Statement: The authors are accountable for all aspects of the work in ensuring that questions related to the accuracy or integrity of any part of the work are appropriately investigated and resolved. The study was conducted in accordance with the Declaration of Helsinki (as revised in 2013). The study was approved by institutional ethics committee of CHU de Rouen (No.: E2021-22) and individual consent for this retrospective analysis was waived.

Open Access Statement: This is an Open Access article distributed in accordance with the Creative Commons Attribution-NonCommercial-NoDerivs 4.0 International License (CC BY-NC-ND 4.0), which permits the noncommercial replication and distribution of the article with the strict proviso that no changes or edits are made and the original work is properly cited (including links to both the formal publication through the relevant DOI and the license). See: https://creativecommons.org/licenses/by-nc-nd/4.0/.

\section{References}

1. Ljungberg B, Campbell SC, Cho HY, et al. The 
Epidemiology of Renal Cell Carcinoma. Eur Urol 2011;60:615-21.

2. Ljungberg B, Albiges L, Abu-Ghanem Y, et al. European Association of Urology Guidelines on Renal Cell Carcinoma: The 2019 Update. Eur Urol 2019;75:799-810.

3. Graves A, Hessamodini H, Wong G, et al. Metastatic renal cell carcinoma: update on epidemiology, genetics, and therapeutic modalities. Immunotargets Ther 2013;2:73-90.

4. Bray F, Ferlay J, Soerjomataram I, et al. Global cancer statistics 2018: GLOBOCAN estimates of incidence and mortality worldwide for 36 cancers in 185 countries. CA Cancer J Clin 2018;68:394-424.

5. Feliu J, Heredia-Soto V, Gironés R, et al. Management of the toxicity of chemotherapy and targeted therapies in elderly cancer patients. Clin Transl Oncol 2020;22:457-67.

6. Lalani AA, Bossé D, McGregor BA, et al. Immunotherapy in the Elderly. Eur Urol Focus 2017;3:403-12.

7. von Elm E, Altman DG, Egger M, et al. The Strengthening the Reporting of Observational Studies in Epidemiology (STROBE) statement: guidelines for reporting observational studies. J Clin Epidemiol 2008;61:344-9.

8. Charlson ME, Pompei P, Ales KL, et al. A new method of classifying prognostic comorbidity in longitudinal studies: Development and validation. J Chron Dis 1987;40:373-83.

9. Ko JJ, Xie W, Kroeger N, et al. The International Metastatic Renal Cell Carcinoma Database Consortium model as a prognostic tool in patients with metastatic renal cell carcinoma previously treated with first-line targeted therapy: a population-based study. Lancet Oncol 2015;16:293-300.

10. Therasse P, Arbuck SG, Eisenhauer EA, et al. New guidelines to evaluate the response to treatment in solid tumors. European Organization for Research and Treatment of Cancer, National Cancer Institute of the United States, National Cancer Institute of Canada. J Natl Cancer Inst 2000;92:205-16.

11. Hutson TE, Bukowski RM, Rini BI, et al. Efficacy and safety of sunitinib in elderly patients with metastatic renal

Cite this article as: Dupuis HGA, Chebbi A, Surlemont L, Rigal O, Di Fiore F, Pfister C, Nouhaud FX. Efficacy and safety of anti-vascular endothelial growth factor therapies in older patients for first line treatment of metastatic renal cell carcinoma. Transl Androl Urol 2021;10(6):2418-2426. doi: 10.21037/tau-20-1481 cell carcinoma. Br J Cancer 2014;110:1125-32.

12. Eisen T, Oudard S, Szczylik C, et al. Sorafenib for Older Patients With Renal Cell Carcinoma: Subset Analysis From a Randomized Trial. J Natl Cancer Inst 2008; 100:1454-63.

13. Bukowski RM, Stadler WM, McDermott DF, et al. Safety and Efficacy of Sorafenib in Elderly Patients Treated in the North American Advanced Renal Cell Carcinoma Sorafenib Expanded Access Program. Oncology 2010;78:340-7.

14. Poprach A, Lakomy R, Bortlicek Z, et al. Efficacy of Sunitinib in Elderly Patients with Metastatic Renal Cell Carcinoma: Data from Real-World Clinical Practice. Drugs Aging 2016;33:655-63.

15. Gore ME, Szczylik C, Porta C, et al. Final results from the large sunitinib global expanded-access trial in metastatic renal cell carcinoma. Br J Cancer 2015;113:12-9.

16. Procopio G, Bellmunt J, Dutcher J, et al. Sorafenib tolerability in elderly patients with advanced renal cell carcinoma: results from a large pooled analysis. $\mathrm{Br} \mathrm{J}$ Cancer 2013;108:311-8.

17. Nouhaud FX, Pfister C, Defortescu G, et al. Baseline chronic kidney disease is associated with toxicity and survival in patients treated with targeted therapies for metastatic renal cell carcinoma. Anticancer Drugs 2015;26:866-71.

18. Vogelzang NJ, Pal SK, Ghate SR, et al. Clinical and Economic Outcomes in Elderly Advanced Renal Cell Carcinoma Patients Starting Pazopanib or Sunitinib Treatment: A Retrospective Medicare Claims Analysis. Adv Ther 2017;34:2452-65.

19. Motzer RJ, Escudier B, Tomczak P, et al. Axitinib versus sorafenib as second-line treatment for advanced renal cell carcinoma: overall survival analysis and updated results from a randomised phase 3 trial. Lancet Oncol 2013;14:552-62.

20. Neuzillet Y, Albrand G, Caillet P, et al. Specificity of the management of metastatic renal cancer in the older patient. Prog Urol 2019;29:874-95. 